\title{
Autosomal dominant intermediate Charcot-Marie-Tooth disease type B
}

INSERM

\section{Source}

INSERM. (1999). Orphanet: an online rare disease and orphan drug data base. Autosomal dominant intermediate Charcot-Marie-Tooth disease type B. ORPHA:100044

Autosomal dominant intermediate Charcot-Marie-Tooth disease type $B$ is a rare hereditary motor and sensory neuropathy characterized by intermediate motor median nerve conduction velocities (usually between 25 and $45 \mathrm{~m} / \mathrm{s}$ ) and signs of both demyelination and axonal degeneration in nerve biopsies. It presents with mild to moderately severe, slowly progressive usual clinical features of Charcot-Marie-Tooth disease (muscle weakness and atrophy of the distal extremities, distal sensory loss, reduced or absent deep tendon reflexes, and feet deformities). Other findings include asymptomatic neutropenia and early-onset cataracts. 